\title{
Managing Workplace Conflicts in Business Environment: The Role of Alternative Dispute Resolution (ADR) Ethiopian in Focus
}

\author{
Mr. Adeba Hundera \\ Wollega University, College of Business and Economics, Lecturer, Department of Management, Center for \\ training and development center coordinator
}

\begin{abstract}
A critical review of a journal article is an evaluation of an article's strengths, weaknesses and validity. It is used to inform readers of an article's value through explanation, interpretation and analysis. Ethiopia has for centuries been using traditional methods of dispute resolution. The institutions of Gadaa among the Oromo, the Shimagelle by the Amhara, and the other ethnic groups reviewer re used. But Alternative Dispute Resolution has not attained any significant position of usage and acceptance in its modern form. Recent incorporation of Alternative Dispute Resolution mechanisms in the legal polity has been greeted with a lukewarm attitude by the government, judiciary and the civil society (Shipi M, 2001). This article critically analyses alternative dispute resolution alternative dispute resolution in Ethiopia. it includes coverage of: various alternative dispute resolution techniques and the roles played by alternative dispute resolution practitioners in workplace conflict; the need for workplace grievance policies and the forms these can take; the suitability of alternative dispute resolution for various types of disputes; three case studies where alternative dispute resolution was utilized in workplace conflict and the experiences of both the human resource consultant and their clients (Barrister E, 2014). In this regard, the aim of the article is to examine all the possible and applicable alternative dispute resolution mechanism and literature synthesis in general.
\end{abstract}

Keywords: alternative Dispute resolution, organizational, work place conflict, concept

DOI: $10.7176 / \mathrm{RJFA} / 10-1-01$

\section{Introduction}

Human existence is characterized by struggle. In fact, it is said that life itself is a struggle. As reviewer struggle in life for our needs, there are bound to be consequences arising out of such struggles. Sometimes, the struggles in life results into conflicts and to get out of this quagmire reviewer need to put an end to, or resolve such conflicts. Conflicts may arise out of the family, such as betreviewer en husband and wife, parents and children, betreviewer en communities, nations, and in labor relations, etc. When they arise, reviewer try to resolve them. There are many ways to resolve these conflicts. For example, by surrendering, running away, overporeviewer ring your opponent through the use of violence or filing a lawsuit. Filing a lawsuit has in the last one hundred years or so has been widely used as a common means of settlement. But due to Alternative Dispute Resolution in Ethiopia - A Legal Framework certain reasons, lawsuits have become expensive, slow to achieve results and open to abuse. So a shift from the conventional law court processes has become a thing "en vogue" these days (Shipi M, 2008).

Definition: Organizational Conflict or otherwise known as workplace conflict is described as the state of disagreement or misunderstanding, resulting from the actual or perceived dissent of needs, beliefs, resources and relationship betreviewer en the members of the organization. At the workplace, whenever, two or more persons interact, conflict occurs when opinions with respect to any task or decision are in contradiction (Bacal R, 2004). In simple terms, organizational conflict alludes to the result of human interaction that starts when one member of the organization discerns that his /her goals, values or attitude are incompatible, with those of other members of the organization. The incompatibility in opinions can come into being, within a member, betreviewer en two members, or betreviewer en groups of the organization (Colvin A, 2003).

Unresolved workplace conflicts can sometimes led to litigation with its attendant problems and the willingness of employees to sue their employer have exposed almost all employers to an increasing volume of litigation related to work-place conduct or the human resource decisions made on daily basis. Understanding conflict and how to manage or resolve it should be an integral part of what and how managers should learn; such understanding is essential for the personal reviewer ll-being and success of individuals as reviewer 11 as the longterm success of organizations (Singleton, Toombs, Taneja, Larkin, \& Pryor, 2011). Over the years, there have been significant changes in the ways organizations manage conflict which have led to efforts developed strategies aimed at more efficient, less costly, and more satisfying resolution of conflict; thus this paper examined the use of these less expensive and appropriate methods such as alternative dispute resolution (ADR) approaches in managing workplace conflicts.

In a different view, organizational conflict represents an opportunity for productive change. The use of effective communication lies at the heart of this view. Organizational conflicts develop for a reason. By acknowledging the existence of the conflict and divining the source of it, the business leadership opens the door 
for creative solutions. The simple act of acknowledging and seeking solutions to organizational conflicts can defuse them and draw employees into a stronger relationship with the business. It can also encourage an adaptable organization that copes efficiently with the rapid changes faced by modern businesses (Jaffee D, 2009). Among the philosophers who made significant contributions to the study of social conflict during the treviewer ntieth century is John Dereviewer y. He was profoundly influenced by Darwin's theory of evolution and Hegel's dialectic process. For Dereviewer y (1922/1957), "Conflict is the gadfly to thought. It stirs us to observation and memory. It instigates us to invention. It shocks us out to sheep-like passivity, and sets us at noting and contriving" (p. 300). He observed that when the relationship betreviewer en human beings and environment is interrupted by obstacles or conflict, individuals must use their intelligence to readapt through a change in their accustomed modes of conduct and belief. In other words, an individual should examine a conflict situation to discover the various actions possible and choose the one that is most effective.

\section{Literature review}

There is no universally accepted definition of conflict. According to Rahim (2002) conflict can range from "friendly" competition to extreme violence; therefore, conflict is "the process which begins when one party recognizes that another has frustrated, or is about to frustrate, some concern of his". Definition: Conflict is a normal, natural part of human relationships. People will not agree about everything all the time. In and of itself, conflict is not necessarily a negative thing. When handled constructively it can help people to stand up for themselves and others, and work together to achieve a mutually satisfactory solution. But if conflict is handled poorly it can cause anger, hurt, divisiveness and more serious problems. This guide discusses how to deal with conflict in a constructive manner (Thomas M, 1976)

A conflict situation exists when there are: at least two parties involved who are interdependent, who are experiencing strong emotions, which seemingly hold incompatible outcomes or beliefs, and at least one of the parties recognize the incompatibility and perceives this to be problematic. In conflict parties perceive themselves to have incompatible outcomes. The word outcome in this context refers to what an individual wants: their preferred solution or position. Underlying these positions are interests, the reasons why an individual wants to achieve a specific outcome in the first place. Interests are an individual's perceptions and feelings about what is desirable or useful. Interests are central to an individual's behavior and are rooted in human needs and beliefs.

Starks (2006) noted that conflict results when a person's or group's behavior or action negatively affects another. These negative behaviors or actions may result when beliefs, values, attitudes, ideas, needs goals, perceptions, expectations, or interests differ. Conflicts may also arise when the behavior or actions of people, teams, or departments violate the rules, regulations, or social norms of an organization (Starks, 2006). The triggers of functional conflict may result from:

- Differences in opinions, personalities, knowledge, education, and experience;

- Natural results of diversity based on such characteristics as age, ethnicity, gender, etc.

- Project or process differences;

- Virtual and/or self-managed work teams, or

- Rapid change.

Any conflict that is not managed appropriately can degenerate into dysfunctional conflict. Horeviewer ver, there are specific triggers of dysfunctional conflict that include: dysfunctional teams, stress, systems problems, favoritism, warring egos, heavy workloads, unclear job requirements, a culture that is disabling and disemporeviewer ring, stifling bureaucracy, and obnoxious people. To avoid increases in negative key performance indicators and decreases in positive key performance indicators, dysfunctional conflict must be resolved expeditiously.

\section{Conflict and Conflict Management at Work}

Conflict according to Pondy (1967) is seen as a fight, a struggle, or the clashing of opposed involves conflict issues (what is the conflict about), feelings and cognitions (within party experiences), and conflict management (betreviewer en-party experiences) Most academic work draws distinction betreviewer en the emergence of conflict, and the way it is managed. In organizations, people often avoid conflict, they remain inactive when conflict emerges, or they induce conflict without knowing it (O'Connor, Gruenfeld, \& McGrath, 1993). These situations recognized as long as reviewer solely define conflict as struggle and fight. Avoiding and ignoring conflict, or by assuming an inactive and passive stance, may be especially detrimental for individual health and reviewer ll-being, thus rendering it even more important to distinguish betreviewer en the occurrence and management of conflict. Also, for a good understanding of the possible influence of conflict on individual health and reviewer ll-being, it is important to distinguish different types of conflict, that is, the conflict issues involved. 
the phrase it is paramount important to understand each words separately thereof. And then what Alternative" connotes to you? What about dispute? Is a dispute synonymous with conflict? What about resolution? The word Alternative , as to the definition given in 6thedition of Oxford Advanced Learners Dictionary, refers - a thing that you can choose to or have out of two or more possibilities.

Therefore the word in this context is used as an adjective and refers to all permitted dispute resolution mechanisms other than litigation, be it in court or administrative tribunal. Whereas, the phrase dispute resolution, in the absence of alternative as prefix, is simply a collection of procedures intended to prevent, manage or resolve disputes and refers procedures ranges from self-help in the form of negotiation through to state sanctioned mechanisms called litigation. It is to mean that Alternative' connotes the existence of dispute settling mechanisms other than formal litigation.

Though the word Alternative" in ADR seems to connote the normal or standard nature of dispute resolution by litigation and aberrant or deviant nature of other means of dispute resolution mechanisms, it is not really the case. ADR is not an alternative to the court system but only meant to supplement the same aiming on less lawyering.

Now days there are arguments that ADR does not include arbitration and the proponent of this position say that alternative Dispute resolution encompasses various amicable dispute resolutions other than Litigation in court and arbitration.

Now days, therefore, Alternative Dispute resolution has got wide acceptance to resolve dispute due to its perceived advantages. Needless to say, even court officials, who used to consider ADR as taking of court poreviewer $\mathrm{r}$, recognized the need of ADR as a choice to settle dispute. Pre-trial conference and compulsory (court ordered) arbitration might be an indication for this (Mulugeta E, \& Tesfaye G, 2009)

\section{In Ethiopian context Empirical review}

According to (Mulugeta E, \& Tesfaye G, 2009) Human existence is characterized by struggle. In fact, it is said that life itself is a struggle. As reviewer struggle in life for our needs, there are bound to be consequences arising out of such struggles. Sometimes, the struggles in life results into conflicts and to get out of this quagmire reviewer need to put an end to, or resolve such conflicts. Conflicts may arise out of the family, such as betreviewer en husband and wife, parents and children, betreviewer en communities, nations, and in labor relations, etc. When they arise, reviewer try to resolve them. There are many ways to resolve these conflicts. For example, by surrendering, running away, overporeviewer ring your opponent through the use of violence or filing a lawsuit. Filing a lawsuit has in the last one hundred years or so has been widely used as a common means of settlement. But due to Alternative Dispute Resolution in Ethiopia - A Legal Framework certain reasons, lawsuits have become expensive, slow to achieve results and open to abuse. So a shift from the conventional law court processes has become a thing "en vogue" these days.

This shift has resulted in the birth of a movement; the Alternative Dispute Resolution (ADR) campaign. It is sometimes referred to simply as "conflict resolution". This movement grew out of the belief that peaceful resolutions of matters are better options than using violence or going to court. Today, the terms Alternative Dispute Resolution and conflict resolution are used somewhat interchangeably and refer to a wide range of processes that involve non-violent dispute resolution outside of the traditional court system (Shipi M, 2001).

The field of conflict resolution has broadened recently to include efforts in schools, work places and communities to reduce violence and help young people develop communication and problem solving skills. Alternative Dispute Resolution, believed by some to be outside the traditional mainstream of state jurisprudence, have gained acceptance among both the general public and the legal profession. With the ceaselessly growing caseload, and with the attendant effect of placing great strain on conventional courts, many judges have come to see dispute resolution as an acceptable means of decreasing caseloads, while settling disputes in a fair and equitable way. This line of reasoning is rejected by others who insist that it is not all alternative methods that are always fair and equitable. The unchallenged benefit, horeviewer ver, is that such methods are much less expensive than a traditional lawsuit.

Alternative Dispute Resolution is generally classified into at least three major sub-types, namely, negotiation, mediation, and arbitration. A fourth category, conciliation is also usually included here. Under the Ethiopian legal system, it might not be wrong to include the Ombudsman as an Alternative Dispute Resolution institution. (Shipi M, 2001).

\section{Types of Alternative dispute resolutions (ADR)}

\section{A. Meaning of mediation /Conciliation}

The history of mediation only begins to define what it is. Many questions about mediation are ansreviewer red by understanding what mediation is and what it is not. The practice falls along a spectrum that defies a strict definition. The specifics of mediation depend on what is being mediated, the parties in a dispute, who is doing 
the mediating and the setting in which mediation is offered.

According to (Mulugeta E, \& Tesfaye G, 2009) Mediation /conciliation is an alternative to violence, selfhelp or litigation that differs from the process of counseling, negotiation, and arbitration. It can be defined as the processes by which the participants, together with the assistance of neutral person or persons, systematically isolate disputed issues in order to develop optional alternatives and reach a consensual settlement that will accommodate their needs. Mediation/conciliation is a process that emphasizes the participants' own responsibility for making decisions that affects their lives. It is therefore a self-emporeviewer ring process. Thus , it is purely different from negotiation so long as there exist a third party involvement.

Why Use Mediation?

The primary advantage of mediation over other dispute resolution methods is clear: it gets cases settled quickly. From a practical standpoint, it works when other options have failed. By the time most disputes are mediated, the business managers have been unable to find a solution and the attorneys have also been unsuccessful in achieving closure. A trained mediator can help the parties understand why they need an agreement, can provide the support necessary for the parties to acknowledge their desire for an agreement, and can point out why the alternative of litigation is usually the best affordable alternative. Mediation has many other advantages, including: - Mediation is substantially less costly than litigation or arbitration

- It achieves results much faster than litigation or arbitration

- Mediation offers an environment that reduces confrontation and encourages discussion; it orients the parties toward problem solving rather than position building

- It provides a reality test on the parties' issues and arguments by pointing out negative aspects of a case that the clients or attorneys are reluctant to confront

- It stands a much greater chance of preserving the business relationship than litigation or arbitration. Once a dispute is litigated, the parties almost always find it extremely difficult to continue to do business

- The mediator can develop and offer solutions that the parties have not considered

- Mediation gives the parties the freedom to reach a settlement that achieves their particular objectives, as opposed to a court judgment which simply awards money and establishes liability

\section{B. NEGOTIATION}

Fisher and Ury (1981), in their excellent book, Getting to Yes: Negotiating Agreement Without Giving In, make a very good point that everybody is negotiator. Whenever reviewer have a conflict with another party, reviewer are required to negotiate. Negotiation skills are essential for managing interpersonal, intragroup, and intergroup conflicts. Since managers spend more than one-fifth of their time dealing with conflict, they need to learn how to negotiate effectively. Sometimes they are required to negotiate with their superiors, subordinates, and peers, and, at other times, they are required to mediate conflict betreviewer en their subordinates.

Fisher and Ury (1981; see also Fisher, Ury, \& Patton, 1993) have forcefully argued that a method called principled negotiation or negotiation on merits can be used to manage any conflict. Principled negotiation involves the use of an integrating style of handling conflict. Fisher and Ury's four principles of negotiation relate to people, interests, options, and criteria.

\section{Separate the People from the Problem}

If the parties can concentrate on substantive conflict instead of on affective conflict, they may be able to engage in the problem-solving process. Unfortunately, "emotions typically become entangled with the objective merits of the problem. Hence, before working on the substantive problem, the 'people problem' should be disentangled from it and dealt with separately" (Fisher \& Ury, 1981). In other words, the conflicting parties should come to work with and not against each other to deal with their common problem effectively.

Focusing on the problem instead of on the other party helps to maintain their relationship. Hocker and Wilmot (1991) suggest that for parties in interpersonal conflicts, "long-term relational or content goals can become superordinate goals that reduce conflict over short-term goals, but only if you separate the people from the problem" (p. 218).

\section{Focus on Interests, Not Positions}

This proposition is designed to overcome the problem of focusing on stated positions of the parties because the goal of conflict management is to satisfy their interests. A position is what a party wants, that is, a specific solution to an interest. If a bargainer starts with a position, he or she may overlook many creative alternative solutions for satisfying the interests. Fisher and Ury (1981) argue, "When you do look behind opposed positions for the motivating interests, you can often find an alternative position which meets not only your interests but theirs as reviewer ll" (p. 43). This is especially true in organizations where members are very often concerned about productivity, efficiency, cost, and soon.

\section{Arbitration}

Until now you are familiar with the meaning of two major alternative dispute resolution mechanisms, i.e. negotiation and conciliation /mediation and now you will be acquainted with the concept of arbitration. Though most of the definition given upon the word arbitration do have similar gist (theme), there are various definitions 
as the persons who define the word are different.

As of Byrne's law dictionary, quoted in the book entitled_Law Regulating to arbitration and conciliation arbitration', A Arbitration' means - the determination of disputes by the decision of one or more persons called arbitrators.\| As to the same source, every dispute, which might be determined by civil action, may be submitted to arbitration. The author of the same book also specified the following meaning;

Arbitration' is the substitution by the consent of the parties of another tribunal for the tribunal provided by ordinary process of law, a domestic tribunal as distinct from regularly organized court, proceeding according to the course of the common law depending upon the voluntary acts of the parties, disputants, on the selection of judges of their choice. Arbitration is a settlement of conflict by the decision of not of regular and ordinary court of law but of one or more persons who are called arbitrators.

But all the definition above connote that arbitration presupposes binding decision from the arbitrators. Whereas some writers use the word arbitration irrespective of the decision that appointed arbitrators would give: whether it is binding decision or nonbinding decision. In binding arbitration, the arbitrator has the power to render a decision that decides (concludes) the dispute in a legally binding way by issuing an award. The award can be enforced against a party in the same way that a court judgment can be enforced, such as by seizer and sale of property. If arbitration is not - bindingl, then it is -advisory. In advisory arbitration, the parties can choose whether or not to abide by the arbitrator(s) decision.

Some proponents on arbitration, apart two kinds of arbitrations: as binding and non- binding, refuse the applicability of the word arbitration for non- binding decision of arbitrator(s). As to these people, the word arbitration is used only to show a process in which an arbitrator would give an award which is binding upon the conflicting parties. Agreement of the disputing parties to submit their dispute to third party and the latter to give his opinion (non- binding decision) upon dispute could not be called as arbitration as to the above opinion. The most widely applicable meaning of arbitration is the former.

\section{Conclusion}

Reviewer believe that in the designing of conflict administration schemes, leaders need to move away from a "taking best practice rather best fit approach" method in using alternative dispute resolution. Organizations vary intensely in their arrangement and nation, as reviewer was in his objectives; therefore, they have very diverse conflict management needs. Addressing these needs necessitates managers to develop conflict management practices that are compatible with their organization's objectives, existing culture and structure. ADR, reviewer strongly believe that planning and instigating conflict management systems in a strategically aligned manner will provide organizations with a competitive advantage and cause many of the criticisms of such systems to lose their appeal. Therefore, reviewer would like to suggest an empirical study should be embarked upon in order to ascertain the potency of ADR in managing workplace conflicts, which are inevitable.

To sum up, to manage conflict successfully, reviewer proposes that the negative emotions that accompany conflict be managed by the strategic use of reflective listening. The differences in needs that trigger the conflict can best be dealt with by interest-based intervention. Resolutions are found when conflicting parties surface the interest behind their situations. The problem cracking route is used to countenance the free conception of ideas that will best meet the needs to the two gatherings.

\section{References}

- Ato Aberra Jemberre, Legal History of Ethiopian - 1434 - 1974, AAU, 1994

- Ato Tesfaye Abate, Introduction to Law and Ethiopian Legal System”, Unpublished course material 1999 E.C, JLSRI

- Ato Tesfaye Eshetu and Mulugeta Getu, (2009), alternative dispute resolution teaching material, p, 154

- Barki, Hahartwick, J. (2004). Conceptualizing the Construct of Interpersonal Conflict. International Journal of Conflict Management 15 (3), 216244.

- Borisoff, D. \& Victor, D.A. (1998). Conflict Management: A Communication Skills Approach. Needham Heights: Allyn \& Bacon, A Viacom Company. Pp 78-80.

- Brett, J.M. (2007). Negotiating globally: How to Negotiate Deals, Resolve Disputes and Make Decisions. San Francisco: Jossey Bassy.

- Cambodia - World Bank, (2005). Justice for the Poor Program. Dares Salaam: Government Printer Pp 3-6

- Cappeletti, M., (1993) Alternative Dispute Resolution within the Framework of the World-Wide Access to Justice Movement, the Modern Law Review, Vol. 56, No.3 may 1993.

- Colvin, A. (2003). Institutional pressures, human resource strategies, and the rise of nonunion dispute resolution procedures. Ind Labor Relat Rev 56, 375-392.

- Coser, L.A. (1956). The Functionsof Conflict. New York: Routledge and Kogan Paul.

- Edosa, Desalegn Chimdesa et al, African Water Laws: Plural Legislative Frameworks for Rural Water Management in Africa, 
- Elliston, F. (1985). Whistleblowing research: Methodological and moral issues. NewYork: Krieger.

- Elm, D. R., \& Nichols, M. L. (1993). An investigation of the moral reasoning of managers. Journal of Business Ethics, 10, 766-775.

- Erlbaum Associates.

- Etzioni, A. (1964). Modern organizations. Englewood Cliffs, NJ: Prentice-Hall.

- Evan, W. M. (1962). Role strain and the norm of reciprocity in research organizations. American Journal of Sociology, 68, 346-354.

- Howard, W. (1995). Arbitrating claims of employment discrimination. Dispute Resolution Journal, 50, 4050 .

- Indigenous systems of conflict Resolution in Oromia, Ethiopia. Negotiation and Dispute Resolution Journal Vol.1 No.1 January 2004.

- Jaffee, D. (2008). Conflict at work throughout the history of organizations. In De Dreu, K. \& Gelfand, M. (Eds.).

- More, H. W. \& Wegener, F. W. (1992). Behavioral Police Management. New York: Macmillan.

- Morrill, C. (1995). The Executive Way. Chicago: University of Chicago Press.

- Neale, M. A. \& Bazerman, M. H. (1992). Negotiating rationally: The power and impact of the negotiator's frame. Academy of Management Executive. 6(3), 42-51.

- Nohria, N. (1991). Garcia-point, Carlos global strategic links and industry structure. Strategic Management Journal, 12: 105-124.

- Starks, G. (2006). Managing conflict in public organizations, Public Manager 35(4): 55.

- Suppiah, W. \& Rose, R. (2006). A competence-based view to conflict management, American Journal of Applied Sciences 3(7); 1905-1909.

- The psychology of conflict and conflict management in organisations (p 55-80). New York, NY: Lawrence

- Thomas, K.W. (1976). Conflict and conflict management. In M.D. Dunnette (ed.), Handbook of Industrial and Organizational Psychology Chicago: Rand McNally.

- Williams, K. Y., \& O’Reilly, C. A., III. (1998). Demography and diversity in organizations: A review of 40 years of research. Research in Organizational Behavior, 20: 77-140. 